\title{
ALAT UJI KADAR AIR PADA BUAH KAKAO KERING BERBASIS MIKROKONTROLER ARDUINO
}

\author{
Rut Dias Valentin ${ }^{* 1)}$, Bintang Diwangkara ${ }^{2)}$, Jupriyadi ${ }^{3)}$, Sampurna Dadi Riskiono ${ }^{4)}$ Elin \\ Gusbriana ${ }^{5)}$ \\ ${ }^{1,2)}$ Program Studi Teknik Komputer, Fakultas Teknik dan Ilmu Komputer, Universitas Teknokrat Indonesia \\ Jl. ZA. Pagar Alam No.9 -11, Labuhan Ratu, Bandar Lampung, Indonesia 35132 \\ ${ }^{3,4,5)}$ Program Studi Teknologi Informasi, Fakultas Teknik dan Ilmu Komputer, Universitas Teknokrat Indonesia \\ Jl. ZA. Pagar Alam No.9 -11, Labuhan Ratu, Bandar Lampung, Indonesia 35132 \\ Email: ${ }^{1}$ rutdiasv@teknokrat.ac.id
}

\begin{abstract}
Currently, the cocoa bean (Theobromacacao L) is one of the agricultural products that has a high selling price. One of the stages in processing cocoa beans is the process of selecting the quality of water content of cocoa beans. Here farmers have difficulty in checking the water content because it is very influential in determining the selling price. Based on this, the researchers made a water content test tool with the implementation of the Soil Moisture sensor, programmed and made using the Arduino IDE on the Arduino UNO R3 microcontroller which is very easy to use just plugging into a pile of cocoa beans that have been collected in a container making it easier for farmers to take the decision to sell or re-dry it so that farmers do not lose. The results of reading the data from the soil mosture sensor researchers used an LCD monitor as a test result viewer, green LEDs for good water content, yellow LEDs for moderate water content, and red LEDs for high water content. The results showed that testing using a container in which there was already cocoa beans in the amount of $1 \mathrm{~kg}$ with good water content conditions results from the tools sold were $6 \%$ and the research tool was $6.5 \%$ so it could be concluded that the tools made could be used to measure levels cocoa bean water with a small error rate of $0.5 \%$.
\end{abstract}

Keywords: kakao, LED, microcontroller

\section{Abstrak}

Saat ini biji kakao (TheobromacacaoL) merupakan salah satu hasil pertanian yang memiliki harga jual yang cukup tinggi. Salah satu tahapan dalam pengolahan biji kakao adalah proses pemilihan kualitas kadar air biji kakao. Disini para petani mengalami kesulitan dalam mengecek kadar air karena sangat berpengaruh dalam penetuan harga jualnya. Berdasarkan hal tersebut peneliti membuat sebuah alat uji kadar air biji kakao dengan implementasi menggunakan sensor Soil Moisture, diprogram dan dibuat menggunakan Arduino IDE pada mikrokontroler Arduino UNO R3 yang sangat mudah penggunaanya dengan menancapkan ketumpukan biji kakao yang sudah dikumpulkan dalam wadah sehingga mempermudah petani dalam mengambil keputusan untuk menjual atau menjemurnya kembali supaya petani tidak rugi. Hasil pembacaan data dari sensor soil mosture peneliti menggunakan LCD monitor sebagai penampil hasil uji, LED warna hijau untuk kadar air bagus, LED warna kuning untuk kadar air sedang, dan LED warna merah untuk kadar air tinggi. Hasil penelitian memperlihatkan pengujian yang menggunakan wadah yang didalamnya sudah terdapat biji kakao dalam jumlah $1 \mathrm{~kg}$ dengan kondisi kadar air bagus hasil dari alat yang dijual yaitu $6 \%$ dan pada alat penelitian $6.5 \%$ jadi dapat diambil kesimpulan alat yang dibuat dapat digunakan untuk mengukur kadar air biji kakao dengan tingkat error yang kecil sebesar $0.5 \%$.

Kata Kunci: kakao, LED, mikrokontroler

\section{Pendahuluan}

Kakao merupakan salah satu hasil perkebunan yang dapat memberikan konstribusi untuk peningkatan devisa Indonesia selain itu kakao memiliki nilai ekonomis yang tinggi [1]. Produksi kakao semakin meningkat dan pemanfaatan kakao sangat banyak [2] mulai dari biji sampai lemaknya dapat dimanfaatkan menjadi produk. Sebagai salah satu penghasil kakao, Indonesia harus dapat meningkatkan mutu biji kakao menjadi sebuah produk agar dapat bersaing dengan negara-negara penghasil kakao lainnya sehingga mendapatkan keuntungan yang optimal [3][4]. Peningkatan produksi hasil pertanian dapat dilakukan dengan memangaatkan kemajuan teknologi [5].

Dalam pemanfaatan mikrokontroler, pembuatan model alat uji kadar air pada kakao kering berbasis mikrokontroler Arduino. Pengujian alat dalam botol dengan menggunakan sensor kadar air, dan juga LCD monitor untuk menampilkan data yang dikirim oleh sensor. Alat ini akan mempermudah pengusaha biji kakao untuk mengetahui nilai kadar air yang berada dalam suatu wadah dan untuk mengetahui nilai kadar air yang bagus dan pengembang menggunakan LED sebagian kode warna agar lebih mudah mengetahui kualitas yang baik. Disini para petani mengalami kesulitan dalam mengecek kadar air karena sangat berpengaruh dalam penetuan harga jualnya. Permasalahan umum petani yang 
banyak ditemukan dalam pengolahan biji kakao adalah pengetahuan petani yang kurang dengan pengolahannya masih menggunakan teknik pengeringan yang tradisonal yang mengandalkan pengeringan dari sinar matahari dan petani hanya bermodal pengalaman saja namun tidak berpacu pada prosedur-prosedur yang benar sehingga kurangnya kualitas biji kakao yang baik dan berdampak merugikan bagi petani kakao [6].

Kemajuan teknologi yang terjadi dapat dimanfaatkan dalam mempermudah pekerjaan manusia [7], yang memungkinkan untuk melakukan suatu inovasi berdasarkan permasalahan yang telah dipaparkan, maka perlu dirancang sebuah alat yang dapat memantau kadar air pada biji kakao. Penelitian sebelumnya telah menerapkan sistem cerdas monitoring temperatur dan kelembaban, yang menghasilkan sistem otomasi dalam mengatur temperatur dan kelembaban pada suatu ruangan berdasarkan informasi pengguna [8]. Inovasi Teknologi yang otomatis menghasilkan peralatan yang memiliki kegunaan yang berbeda namun saling berkaitan satu dengan yang lain sehingga dapat melaksanakan sesuai fungsi secara otomatis [9][10]. Dimana alat ini dapat mengetahui kadar air dan menampilkan data yang di kirim oleh sensor kadar air supaya mendapatkan hasil yang cocok untuk di produksi dan biji yang berkualitas bagi petani kakao. Alat ukur kadar air biji - bijian yang sudah di buat sudah sangat banyak contohnya MD7822 adalah alat ukur biji bijian ini yang sering di gunakan oleh kalangan pengusaha biji kakao namun alat tersebut relatif mahal harganya karena masih sangat sedikit pembuat alat tersebut maka peneliti melakukan inovasi dengan membuat alat uji kadar air pada biji kakao dengan harga yang relative murah dan penggunaannya sangatlah muda bagi pemula. Sehingga diharapkan alat ini dapat menjadi inovasi baru dalam membantu pengguna baik itu petani, pengusaha kakao dan pengelola kakao agar dapat mengetahui kadar air dalam biji kakao agar mendapatkan biji kakao yang berkualitas.

\section{Metode}

Metode penelitian meliputi perancangan perangkat keras dan metode pengujian dan yang menjadi bahan penelitian adalah kadar air pada kakao kering yang dimana sebuah perangkat sensor dituntut untuk bekerja dengan baik dalam keperluan kecepatan sensitivitas dalam pembacaan sensor.

\subsection{Alat dan Bahan}

Adapun alat dan bahan yang dibutuhkan dalam penelitian ini yaitu sebagai berikut :

1. Laptop sebagai media pemrograman dan analisa (Prosessor intel coreTM i3 - 6006U (2.0 GHz, RAM 2GB DDR4, HDD 500GB).

2. Mikrokontroler Arduino UNO R3.

3. Soil Moisture.

4. LCD 16x2 Monochrome.

5. LED (Red,Green, Yellow)

6. Breadboard dan kabel jumper $20 \mathrm{~cm}$

7. Sistem operasi Microsoft Windows 10.

\section{Ardunio IDE.}

\subsection{Desain dan Pembuatan Kerangka Peletakan Sensor}

Berikut adalah desain kerangka yang akan digunakan sebagai wadah peletakan sensor, ditunjukkan pada Gambar 1.

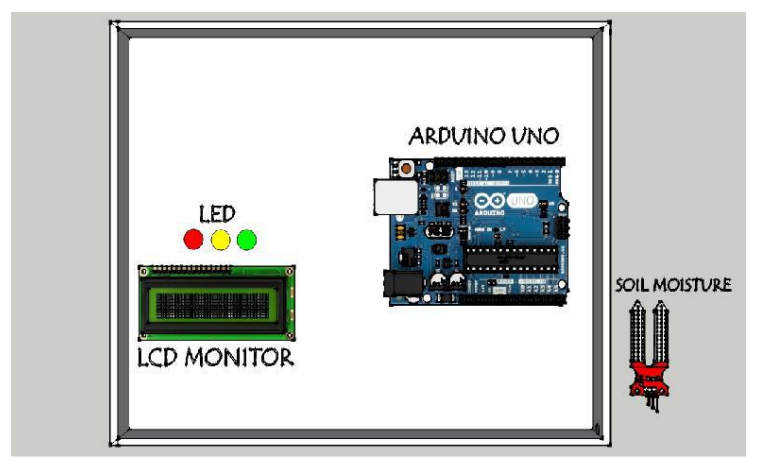

Gambar 1. Kerangka peletakan sensor

\subsection{Desain Arsitektur Elektronika}

Desain arsitektur elektronika merupakan pembahasan yang menggambarkan alur hubungan antara beberapa modul elektronika maupun mekanika yang digunakan, arsitektur elektronika dimulai dari mikrokontroler Arduino UNO R3 kemudian memberikan perintah program terhadap sensor yang di aktifkan selanjutnya sensor Soil Moisture membaca nilai kondisi jika kadar air < 6 maka LED warna hijau akan menyala dan jika kadar air > 6 maka LED warna kuning akan menyala jika > 12 maka LED warna merah akan menyala. sebagai acuan nilai sensor yang akan diproses kembali oleh mikrokontroler Arduino UNO R3. Adapun bagian dari LCD adalah bersifat opsional yang digunakan untuk menguji kadar air hasil dari proses pembacaan sensor Soil Moisture.

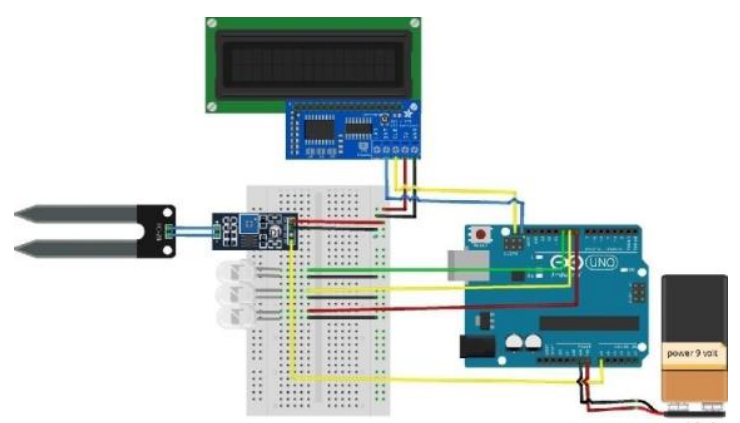

Gambar 2. Arsitektur elektronika

\subsection{Perakitan dan Pemasangan Sensor Serta Modul Elektronika}

Perakitan dan pemasangan sensor sesuai desain yang telah dibuat kemudian mengintegrasikan beberapa modul elektronika agar dapat terkoneksiseperti yang ada pada blok diagram berikut. 


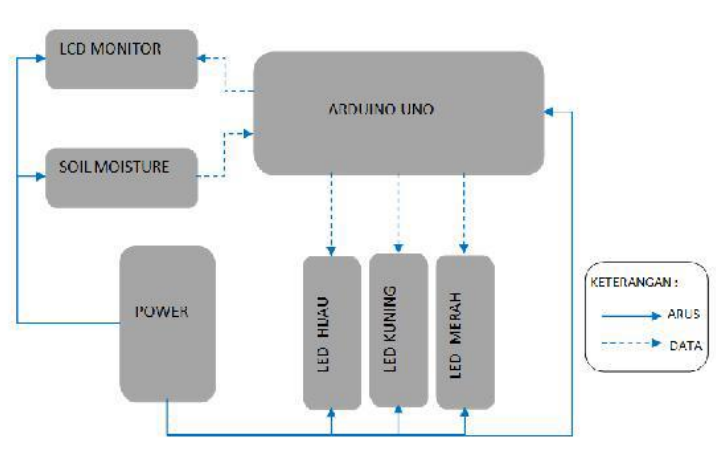

Gambar 3. Blok diagram

Berikut merupakan visual setelah dilakukannya perakitan dan pemasangan rangkaian elektronika yang ditunjukkan pada Gambar 4.

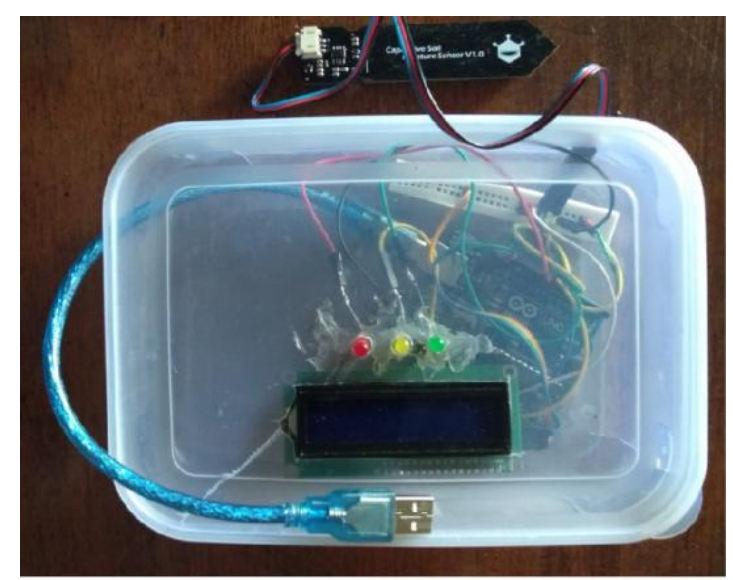

Gambar 4. Sistem kontrol Soil Moisture

\subsection{Kode Program}

Rancangan program menggunakan software Arduino IDE yang akan di implementasikan dalam penelitian dalam bentuk program. Adapun program yang dibuat yaitu seperti berikut.

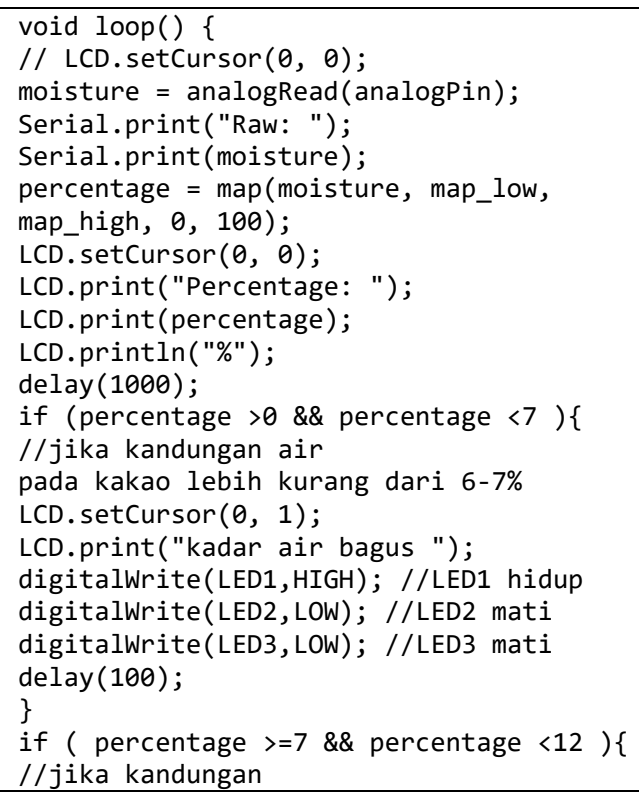

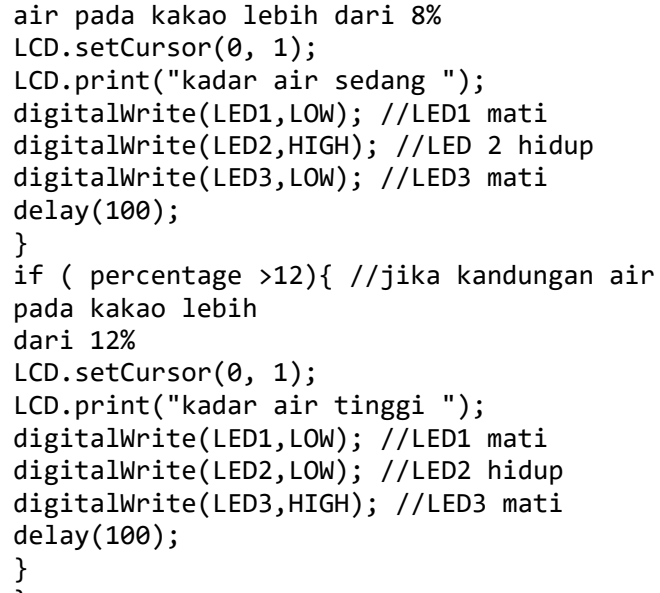

Gambar 5. Program pembacaan data Soil Moisture yaitu kadar air yang ideal untuk mengecek kadar air pada kakao kering.

\subsection{Pengujian}

Pengujian yang dilakukan pada alat uji kadar air pada buah kakao kering meliputi pembacaan sensor Soil Moisture, pengujian tampilan LCD monitor, pengujian output sistem melalui dari LED berwarna. Pengujian pembacaan sensor Soil Moisture dengan cara meletakan sensor pada sebuah objek yaitu biji kakao untuk mengetahui apakah sensor sudah bekerja dengan baik atau tidak. Pengujian tampilan LCD monitor dilakukan untuk mengetahui apakah pengiriman data dari sensor sudah dikirim dengan semestinya atau tidak.

Pengujian LED warna hijau ketika sensor mendeteksi bahwa kadar air $<7 \%$ menunjukan bahwa kadar air pada biji kakao bagus, LED warna kuning ketika sensor mendeteksi bahwa kadar air <12\% menunjukan bahwa kadar air pada biji kakao sedang dan LED warna merah ketika sensor mendeteksi bahwa kadar air $>12 \%$ menunjukan bahwa kadar air pada biji kakao tinggi.

\section{Hasil dan Pembahasan}

\subsection{Pengujian Pembacaan Sensor Soil Moisture}

Pengujian yang dilakukan adalah pembacaan sensor Soil Moisture yang dilakukan dengan cara meletakan sensor Soil Moisture kedalam wadah yang berisi biji kakao, adpaun alat-alat serta langka-langkah pengujian seperti berikut ini:

1. Hubungkan sensor Soil Moisture ke mikrokontroler Arduino UNO dengan jalur komunikasi pin analog.

2. Hubungkan LCD monitor ke mikrokontroler Arduino UNO.

3. Hubungkan LED warna hijau, kuning dan merah masing-masing ke mikrokontroler rduino uno dengan jalur komunikiasi pin digital. 


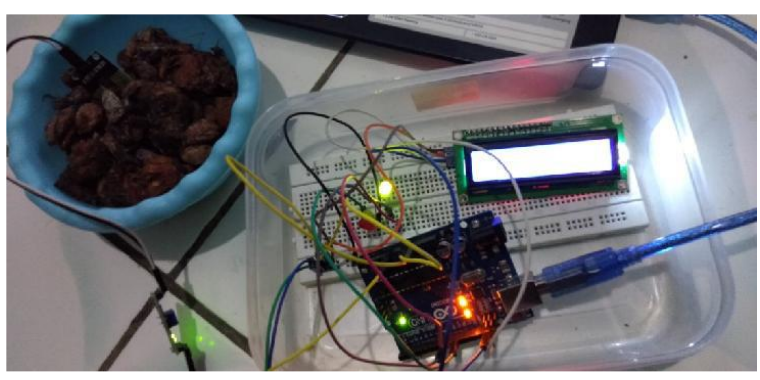

Gambar 6. Rangkaian eletronika yang sudah terhubung

\subsection{Pengujian Tampilan LCD Monitor}

Pengujian tampilan LCD monitor dilakukan dengan pengambilan hasil pembacaan sensor Soil Moisture sampel dengan kadar air $<=12 \%$ menunjukan bahwa kadar air sedang, kemudian dalam pengujian ini juga menggambarkan hasil penggunaan LCD monitor dapat menampilkan hasil dengan baik dan benar sesuai dengan sistem.

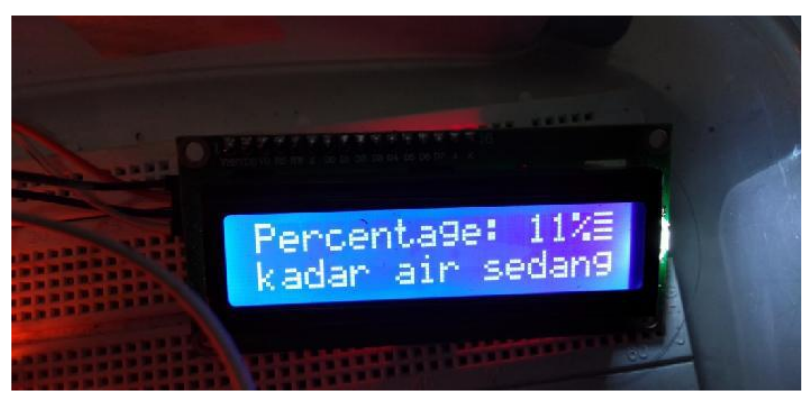

Gambar 7. Hasil pengujian LCD monitor

\subsection{Pengujian LED pada Sistem}

Pengujian LED dilakukan dengan berdasarkan pengambilan hasil pembacaan sensor Soil Moisture dengan kadar air pada biji kakao kemudian dalam pengujian ini juga menggambarkan hasil penggunaan LED berkerja dengan baik.

Tabel 1. Hasil pengujian LED pada sistem

\begin{tabular}{lll}
\hline \multicolumn{1}{c}{ LED } & $\begin{array}{c}\text { Kadar Air Sensor Soil } \\
\text { Moisture }\end{array}$ & Keterangan \\
\hline hijau & $\leq 7 \%$ & bagus \\
kuning & $\geq 7 \%$ dan $\leq 12 \%$ & sedang \\
merah & $\geq 12 \%$ & tinggi \\
\hline
\end{tabular}

\subsection{Hasil Uji Coba Alat}

Pengujian menggunakan dua alat uji kadar air biji kakao yaitu dengan alat yang telah dibuat oleh penelitdan alat yang telah di produksi oleh perusahaan. Uji coba ini untuk mencari data hasil pembacaan dua alat tersebut dengan menggunakan media biji kakao yang sama.

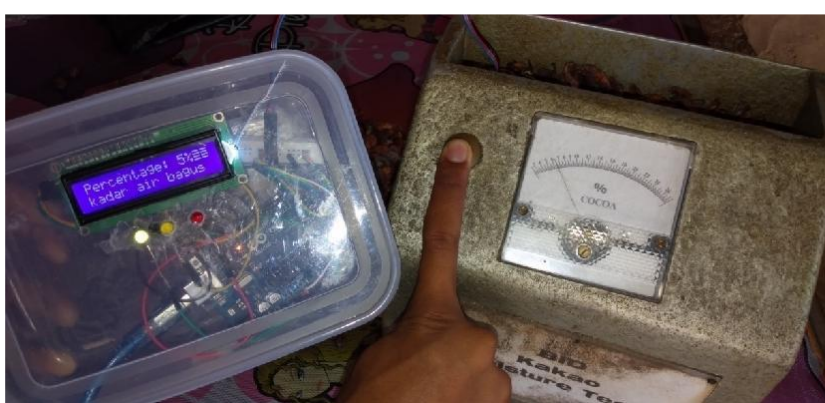

Gambar 8. Proses perbandingan alat

Berdasarkan pengujian yang telah dilakukan didapatkan hasil sebagai berikut.

Tabel 2. Hasil perbandingan alat

\begin{tabular}{llll}
\hline Kadar Air & $\begin{array}{c}\text { Alat yang } \\
\text { Dibuat }\end{array}$ & $\begin{array}{c}\text { Alat yang } \\
\text { Dibeli }\end{array}$ & Error \\
\hline Bagus $(\leq 7 \%)$ & $5 \%$ & $6.2 \%$ & $1.2 \%$ \\
Sedang $(\geq 7 \%$ & $11 \%$ & $11 \%$ & $0 \%$ \\
dan $\leq 12 \%)$ & & & \\
Tinggi $(\geq 12 \%)$ & $19 \%$ & $18.5 \%$ & $+0.5 \%$ \\
\hline
\end{tabular}

\subsection{Pengujian di Beberapa Titik Objek}

Pengujian ini di lakukan pada suatu wadah yang berisi kakao kering yang telah diisi 500 gram biji kakao, terdapat beberapa titik yang telah peniliti berikan pada gambar A, B, C, D yang berada dalam satu wadah dan objek biji kakao kering yang telah di fermentasi selama 4 hari dan terik matahari 40-600C.

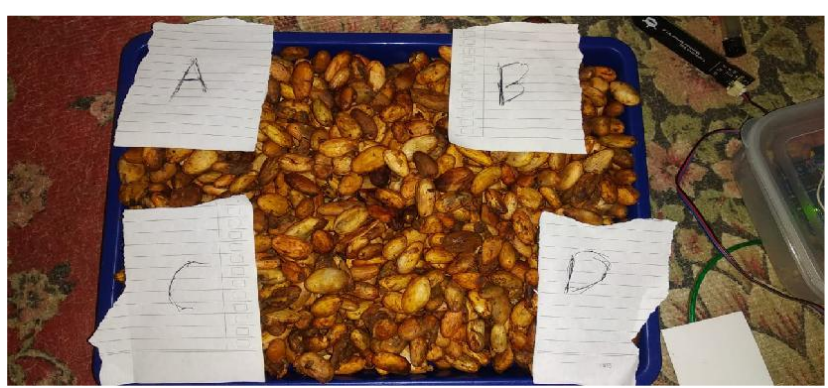

Gambar 9. Pengujian di beberapa titik objek

1. Pengujian pada titik $\mathrm{A}$

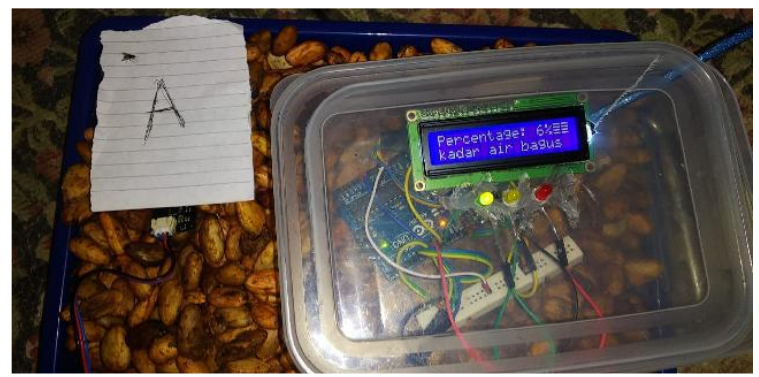

Gambar 10. Pengujian pada titik A

Hasil pengujian pada titik A menunjukan bahwa kadar air pada wadah bagian atas pojok kiri adalah $6 \%$ dan peneliti juga memberika tanda indikator LED warna hijau yang berarti kadar air bagus. 


\section{Pengujian pada titik B}

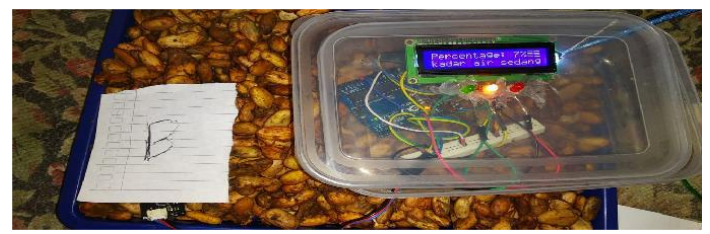

Gambar 11. Pengujian pada titik B

Hasil pengujian menunjukan bahwa kadar air pada wadah bagian bawah pojok kiri adalah $7 \%$ dan peneliti juga memberika tanda indikator LED warna kuning yang berarti kadar air sedang.

3. Pengujian pada titik $\mathrm{C}$

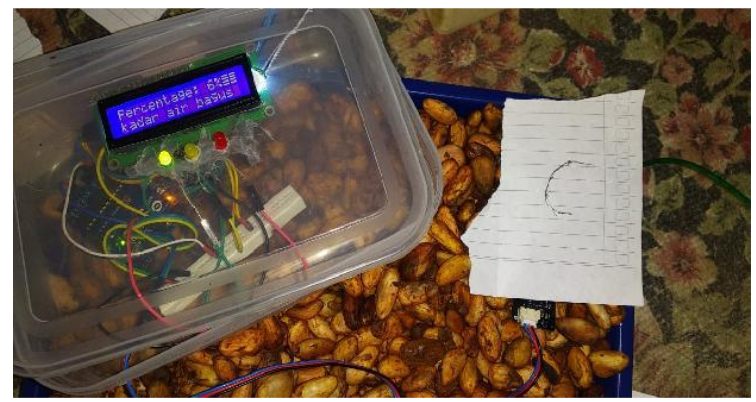

Gambar 12. Pengujian pada titik $C$

Hasil pengujian pada titik $\mathrm{C}$ menunjukan bahwa kadar air pada wadah bagian atas pojok kanan adalah $6 \%$ dan peneliti juga memberika tanda indikator LED warna hijau yang berarti kadar air bagus.

4. Pengujian pada titik D

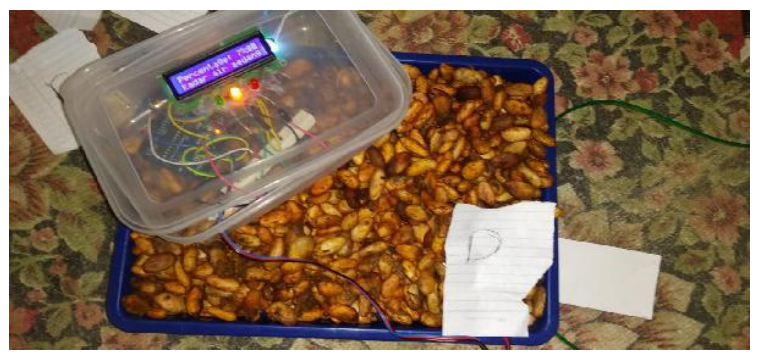

Gambar 13. Pengujian pada titik D

Hasil pengujian pada titik D menunjukan bahwa kadar air pada wadah bagian atas pojok kanan adalah 7\% dan peneliti juga memberikan tanda indikator LED warna kuning yang berarti kadar air sedang.

Dapat disimpulkan hasil keseluruhan dari beberapa titik uji nilai rata-rata yang didapat yaitu $(6+7+6+7) / 4$ $=6.5 \%$ nilai kadar air pada biji coklat yang terdapat diwadah.

\section{Kesimpulan dan Saran}

Berdasarkan hasil perancangan dan pengujian yang telah dilakukan pada alat uji kadar air pada buah kakao kering berbasis mikrokontroler Arduino, baik perangkat keras maupun perangkat lunak dapat diambil beberapa kesimpulan yaitu,

1. Alat yang telah dibuat menggunakan sensor Soil Moisture dapat membantu mengurangi kesalahan penentuan harga untuk memberikan harga yang cocok untuk petani.

2. Hasil pembacaan data dari sensor soil mosture peneliti menggunakan LCD monitor sebagai penampil hasil uji, LED warna hijau untuk kadar air bagus, LED warna kuning untuk kadar air sedang, dan LED warna merah untuk kadar air tinggi.

3. Hasil penelitian memperlihatkan pengujian yang menggunakan wadah yang didalamnya sudah terdapat biji kakao dalam jumlah $1 \mathrm{~kg}$ dengan kondisi kadar air bagus hasil dari alat yang dijual yaitu $6 \%$ dan pada alat penelitian $6.5 \%$ jadi dapat diambil kesimpulan alat yang dibuat dapat digunakan untuk mengukur kadar air biji kakao dengan tingkat error yang kecil.

4. Inovasi alat yang telah di buat menggunakan sensor Soil Moisture tidak hanya perusaahaan besar yang bisa menggunakan alat tersebut namun dikalangan menengah kebawah bisa menggunakan alat tersebut dengan harga yang murah dan cara penggunaan yang sangat mudah. Alat ini dengan mudah mengetahui kadar air saat itu juga dengan hasil pembacaan sensor Soil Moisture yang akan ditampilkan menggunakan LCD monitor dan LED sebagai kode warna dengan keterangan bagus, sedang, atau tinggi.

Setelah melakukan penelitian ini diperoleh beberapa hal yang dapat dijadikan saran untuk pengembangan selanjutnya yaitu dapat melakukan modifikasi pada alat tersebut, diantaranya,

1. Diharapkan untuk menambahkan system memory agar pengecekan beberapa kali masih dapat disimpan.

2. Diharapkan untuk pengembang dapat menggunakan teknologi $I o T$ dan perangkat mobile agar komunikasi selanjutnya jauh lebih baik dari sebelumnya.

\section{Daftar Pustaka}

[1] Y.G. Lada, S. Supriyanto, dan P. Darmadji, "Pengaruh perendaman biji kakao kering dan bahan alat sangrai terhadap sifat fisik dan profil senyawa volatil kakao sangrai serta sifat sensoris cokelat batang yang dihasilkan," J. Agritech, 2015, doi: 10.22146/agritech.9439.

[2] R.U. Hatmi dan S. Rustijarno, "Teknologi pengolahan biji kakao menuju SNI biji kakao 01-2323-2008", Balai Besar Pengkajian Dan Pengembangan Teknologi Pertanian, 2012.

[3] R. Hayati dan H. Fauzi, "Kajian fermentasi dan suhu pengeringan pada mutu kakao (Theobroma cacao L.)," Jurnal Keteknikan Pertanian, vol. 26, no. 2, 2014

[4] Z. Basri, "Mutu biji kakao hasil sambung samping," Media Litbang Sulteng III, 2010.

[5] A. Nurkholis dan I.S. Sitanggang, "A Spatial Analysis 
Of Soybean Land Suitability Using Spatial Decision Tree Algorithm," in Sixth International Symposium on LAPAN-IPB Satellite (Vol. 11372, p. 113720I), Desember 2019.

[6] M. Yahya, "Alat pengering hasil - hasil pertanian untuk daerah pedesaan di sumatera barat," Jurnal Teknik Mesin (JTM), vol. 3, no. 2, pp. 26-31, 2013.

[7] A. Nurkholis, A. Riyantomo dan M. Tafrikan, "Sistem pakar penyakit lambung menggunakan metode forward chaining," Majalah Ilmiah Momentum, vol. 13, no. 1, 2017.

[8] D.E. Kurniawan, M. Iqbal, J. Friadi, R.I. Borman dan R. Rinaldi. "Smart Monitoring Temperature and Humidity of the Room Server Using Raspberry Pi and Whatsapp Notifications," In Journal of Physics: Conference Series (Vol. 1351, No. 1, p. 012006) IOP Publishing, 2019.

[9] S. Samsugi dan A. Burlian, "Sistem penjadwalan pompa air otomatis pada aquaponik menggunakan mikrokontrol Arduino UNO R3," Prosiding Semnastek, vol. 1, no. 1, 2019.

[10] S. Samsugi, N. Neneng dan B. Aditama, "IoT: kendali dan otomatisasi si parmin (studi kasus peternak Desa Galih Lunik Lampung Selatan)," Prosiding Semnastek, vol. 1, no. 1, 2018. 